OPEN ACCESS

Edited by:

Colleen B. Jonsson,

University of Tennessee Health Science Center, United States

Reviewed by:

Jeremy V. Camp,

Veterinärmedizinische Universität

Wien, Austria

Shintaro Kobayashi

Hokkaido University, Japan

${ }^{*}$ Correspondence:

Alan G. Goodman alan.goodman@wsu.edu

Received: 23 January 2018 Accepted: 16 March 2018 Published: 03 April 2018

Citation:

Ahlers LRH and Goodman AG (2018) The Immune Responses of the Animal Hosts of West Nile Virus: A

Comparison of Insects, Birds, and Mammals.

Front. Cell. Infect. Microbiol. 8:96. doi: 10.3389/fcimb.2018.00096

\section{The Immune Responses of the Animal Hosts of West Nile Virus: A Comparison of Insects, Birds, and Mammals}

\author{
Laura R. H. Ahlers ${ }^{1}$ and Alan G. Goodman ${ }^{1,2 *}$ \\ ${ }^{1}$ School of Molecular Biosciences, Washington State University, Pullman, WA, United States, ${ }^{2}$ Paul G. Allen School for \\ Global Animal Health, College of Veterinary Medicine, Washington State University, Pullman, WA, United States
}

Vector-borne diseases, including arboviruses, pose a serious threat to public health worldwide. Arboviruses of the flavivirus genus, such as Zika virus (ZIKV), dengue virus, yellow fever virus (YFV), and West Nile virus (WNV), are transmitted to humans from insect vectors and can cause serious disease. In 2017, over 2,000 reported cases of WNV virus infection occurred in the United States, with two-thirds of cases classified as neuroinvasive. WNV transmission cycles through two different animal populations: birds and mosquitoes. Mammals, particularly humans and horses, can become infected through mosquito bites and represent dead-end hosts of WNV infection. Because WNV can infect diverse species, research on this arbovirus has investigated the host response in mosquitoes, birds, humans, and horses. With the growing geographical range of the WNV mosquito vector and increased human exposure, improved surveillance and treatment of the infection will enhance public health in areas where WNV is endemic. In this review, we survey the bionomics of mosquito species involved in Nearctic WNV transmission. Subsequently, we describe the known immune response pathways that counter WNV infection in insects, birds, and mammals, as well as the mechanisms known to curb viral infection. Moreover, we discuss the bacterium Wolbachia and its involvement in reducing flavivirus titer in insects. Finally, we highlight the similarities of the known immune pathways and identify potential targets for future studies aimed at improving antiviral therapeutic and vaccination design.

\section{Keywords: innate immunity, West Nile virus, Culex, host response, vector-borne disease}

\section{INTRODUCTION}

West Nile virus (WNV) belongs to the flavivirus genus, which also includes dengue virus (DENV), yellow fever virus (YFV), and Zika virus (ZIKV). WNV is endemic to the United States (U.S.) and Canada, Africa, Europe, the Middle East, and West Asia (WHO, 2011).WNV has a singlestranded positive-sense RNA genome encoding approximately 11,000 nucleotides. It is translated as a polyprotein and processed into 3 structural and 7 nonstructural viral proteins (reviewed in Brinton, 2013). The virus amplifies, or replicates to high titer (Figures 1A,B), within the bird population, making them likely to transmit the infection to mosquitoes (Figure 1C), primarily of the Culex genus. Mosquitoes can then reinfect the bird population, further perpetuating enzootic 
infection (Figure 1E), or can bridge the infection to mammals, most commonly humans and horses (Figure 1F). It is at this interface that public health becomes a concern. Human symptoms can be mild, presenting with headache, weakness, or fever, or more severe, presenting with meningitis or encephalitis (Petersen et al., 2013). In this review, we discuss mosquito populations in North America with particular attention to species that bridge WNV infection to humans, and then survey the innate immune response pathways of the animals commonly infected with WNV: mosquitoes, birds, horses, and humans. While the adaptive immune response is important for mammalian survival to WNV, this review focuses on innate pathways and rapid immune activation during $\mathrm{WNV}$ infection. We review possible avenues for therapeutic design, including antibodies for passive immunity and the endosymbiont Wolbachia to reduce infection in insects. Lastly, we identify new areas for investigation, especially those focused on vaccine development and disease therapeutics.

\section{CULEX MOSQUITOES AS VECTORS OF INFECTION}

Mosquitoes in the culicine family carry WNV, and each species has a preferred geographical tropism, blood meal host, and daily and seasonal feeding pattern. Culex quinquefasciatus is located between the latitudes $36^{\circ} \mathrm{N}$ and $36^{\circ} \mathrm{S}$ (Barr, 1957), and in the U.S. from coast to coast (Darsie and Ward, 2005). Cx. quinquefasciatus has been observed as far north as $39^{\circ} \mathrm{N}$, giving it some geographical overlap with $C x$. pipiens, which lives above $36^{\circ} \mathrm{N}$ (Barr, 1957). Cx. pipiens ranges north into British Columbia and through Maine. $C x$. tarsalis can be found in most of the U.S., but is not usually found in the easternmost states, likely due to competition with $C x$. salinarius, which prefers warmer, coastal temperatures (Darsie and Ward, 2005). Finally, $C x$. restuans is found in more urban areas, as the larvae are better able to tolerate pollution than other mosquito species (Johnson et al., 2015). Culex population genetics, mating patterns, and host selection, with emphasis on data collected in California, has been reviewed by Reisen (2012), which concludes that urbanization will favor $C x$. pipiens and hinder $C x$. tarsalis. While not discussed in Reisen (2012), Cx. restuans is also likely to thrive in metropolitan areas, perhaps making $C x$. pipiens and $C x$. restuans of greatest importance for the study of vector-borne disease.

Although research on Culex mosquitoes in North America has been ongoing for over 70 years, the arrival of WNV to the U.S. spurred deeper research into the species-specific and region-specific differences between Culex mosquitoes that allow them to be enzootic vectors (Figure 1E) and bridges to human infection (Figure 1F). Culex species feed on avian hosts, either as a primary source of blood meal or more opportunistically (Molaei et al., 2006; Reisen, 2012). A variety of studies have investigated the competence of Culex mosquito populations in specific geographic locations to transmit WNV to mammals. In a study completed in Connecticut, researchers found that $C x$. restuans and $C x$. pipiens tend to feed on birds, determined by the presence of bird blood meal, making these important species for enzootic infection. Moreover, $C x$. salinarius is most likely to feed on both vertebrates and birds, making it an important bridge to humans in this region (Molaei et al., 2006). In another study in the northeastern U.S., researchers determined that vector competence can vary over time and is dependent on environmental factors, such as temperature, and genetic factors, such as ancestry. Furthermore, the authors conclude that $C x$. restuans are more likely to transmit WNV than $C x$. pipiens (Kilpatrick et al., 2010).

The Cx. quinquefasciatus mosquitoes are the primary species in the southern U.S. and Mexico. Cx. quinquefasciatus in Cancún and Chetumal often feed on humans, but rarely on birds, so this species is not a likely bridge between bird and human WNV infection (Janssen et al., 2015). However, in East Baton Rouge Parish, Louisiana, Cx. quinquefasciatus frequently feed on avian hosts, as well as human and other mammalian sources of blood meal, suggesting that $C x$. quinquefasicatus is a vector for human transmission of WNV in southern Louisiana (Mackay et al., 2010). In Bernalillo County, New Mexico, researchers determined that $C x$. quinquefasciatus mosquitoes are likely the primary vectors for enzootic infection in birds, but $C x$. tarsalis are more likely the bridge to infect humans, as these mosquitoes feed on both mammals and birds throughout the feeding season (Lujan et al., 2014).

Laboratory studies have further investigated the speciesspecific differences between Culex mosquitoes when infected with WNV. Cx. tarsalis infected with WNV have decreased fecundity and increased feeding rates, but no change in survival (Styer et al., 2007). Conversely, Cx. pipiens show no difference in survival, fecundity, or feeding rates when infected with WNV (Ciota et al., 2011). These findings complicate the ability to predict WNV infection rates in specific mosquitoes. Ciota et al. predicts that susceptible $C x$. pipiens mosquitoes will be maintained in a community, as there is no cost for infection, but there is a cost for resistance. The results in Styer et al. suggest that in $C x$. tarsalis the cost for infection, namely decreased fecundity, may be overcome by an increase in feeding rate. This behavioral compensation is supported by the finding that $C x$. tarsalis have a higher estimated rate of transmission than $C x$. pipiens (Turell et al., 2001, 2002). The same research group determined that $C x$. restuans and $C x$. salinarius are both efficient vectors of WNV infection, while Cx. quinquefasciatus is moderately efficient (Sardelis et al., 2001). Additionally of note, Cx. pipiens can perpetuate WNV infection by vertical transmission (Dohm et al., 2002); consequently multiple generations of mosquitoes are infective (Figure 1D).

Alarmingly, the geographic range of Culex mosquitoes is expanding. Models of $C x$. pipiens and $C x$. tarsalis reveal that climate change is likely to contribute to the expansion of the mosquito population in Canada and extend the WNV transmission season by the year 2050 (Hongoh et al., 2012; Chen et al., 2013). Additionally, Cx. quinquefasciatus season is predicted to increase in length by a few weeks at both the beginning and end of the summer in the U.S. (Morin and Comrie, 2013). Taken together, these models conclude that the geographic range of mosquitoes, and consequently WNV infections, will 


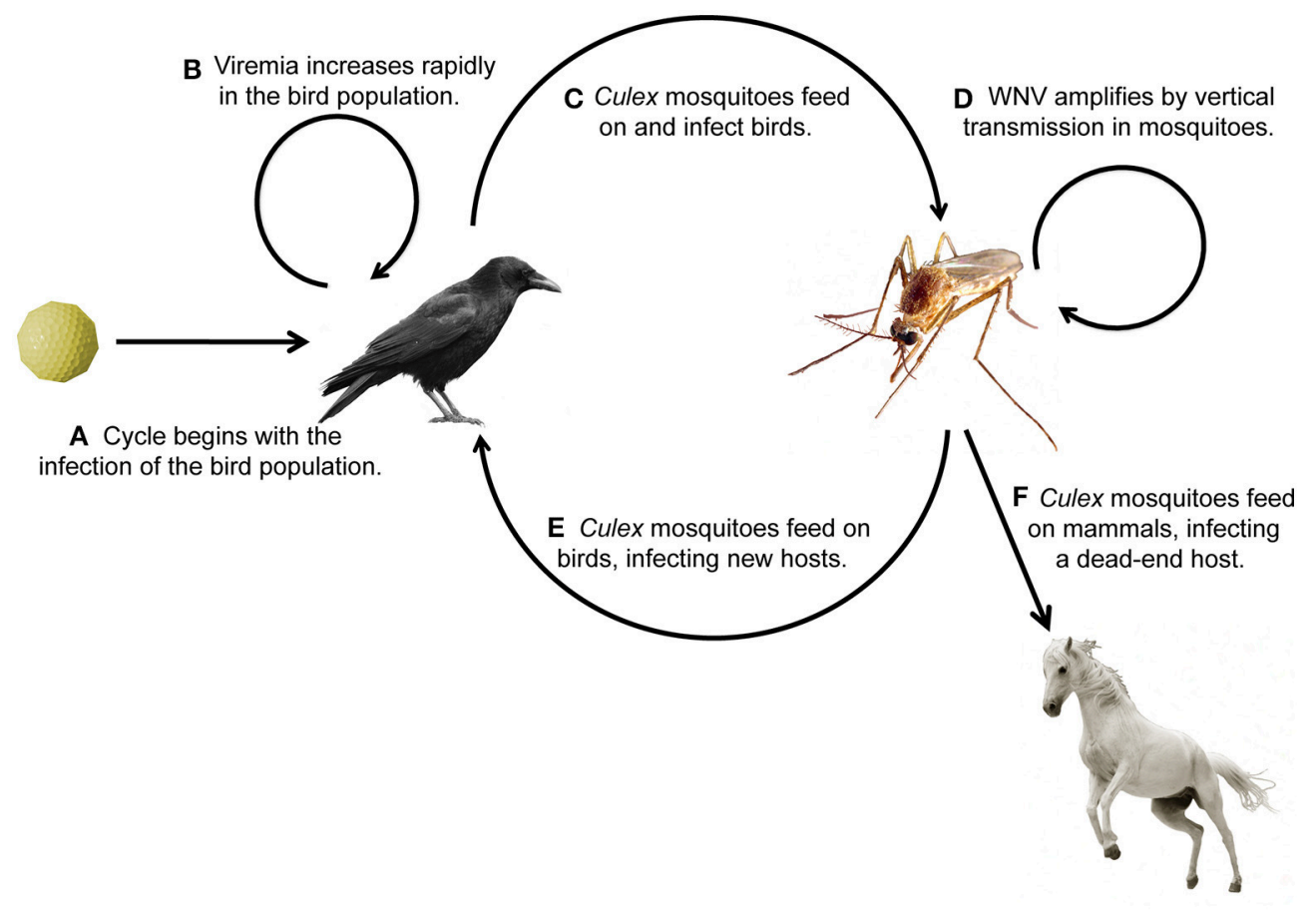

FIGURE 1 | Transmission cycle of West Nile virus through its animal hosts. (A,B) Birds become infected with WNV and viral titer increases, (C,D) birds transmit the infection to mosquitoes, (E) which transmit the infection to birds, causing enzootic infection, or (F) bridge the infection to humans and horses, the common dead-end hosts.

increase. A summary of the effects of climate change on several insect-borne infections is provided in Andersen and Davis (2017).

\section{THE MOSQUITO IMMUNE RESPONSE TO WNV}

Mosquitoes utilize an innate immune response to $\mathrm{WNV}$ to prevent mortality from infection. The RNA interference (RNAi) pathway is conserved across diverse phyla and provides host protection against virus infection, including arboviruses (Olson and Blair, 2015). Dicer-2, the viral nucleic acid sensor of the RNAi pathway, is utilized in the response to WNV infection in $C x$. quinquefasciatus cells, and orally-infected $C x$. quinquefasciatus mosquitoes respond to WNV (Kunjin strain) challenge via the RNAi pathway (Paradkar et al., 2014). In fact, WNV (Kunjin strain) has been shown to antagonize the host RNAi response in Cx. quinquefasciatus by generating viral noncoding sfRNA (subgenomic flavivirus RNA) that interacts with Dicer and Argonaute 2 (Moon et al., 2015). sfRNA is viral genomic RNA that resists degradation by the host cell by forming pseudoknot structures (Jones et al., 2012; Chapman et al., 2014). The RNAi pathway even drives WNV population diversity in both mosquitoes and Drosophila melanogaster, as the RNAi pathway selects for the more diverse virus variant (Brackney et al., 2009, 2015). Like mosquitoes, D. melanogaster utilize the RNAi pathway for resistance to WNV infection, determined by the detection of siRNA (small interfering RNA) (Chotkowski et al., 2008), validating the fruit fly as a possible model organism to study mosquito immunity.

Mosquitoes also utilize the JAK/STAT pathway in the immune response to WNV. Transcriptional profiling reveals that Aedes aegypti mosquitoes utilize this pathway in response to WNV, DENV, and YFV (Colpitts et al., 2011). Mechanistically, in Culex cells the immune response to WNV utilizes a secreted molecule called Vago that, like interferon in mammals, is hypothesized to act as a second messenger to activate the JAK/STAT pathway (Paradkar et al., 2012). Finally, apoptosis, a conserved immediate immune response, occurs in the salivary glands and midgut of $C x$. quinquefasciatus mosquitoes to control viral load (Vaidyanathan and Scott, 2006; Girard et al., 2007).

Lastly, of note, the endosymbiont Wolbachia affects the mosquito host response to WNV. Wolbachia is a bacterium originally identified in Cx. pipiens (Hertig and Wolbach, 1924), reviewed in Johnson (2015). It is estimated that $40 \%$ of all arthropod species (Zug and Hammerstein, 2012) and 7\% of Cx. pipiens mosquitoes in California (Rasgon and Scott, 2004) are infected with Wolbachia. There are a few strains of Wolbachia used in laboratory experiments, discussed in Woolfit et al. (2013): $w \mathrm{Mel}$ was identified in D. melanogaster and is benign (Teixeira et al., 2008), wMelPop was identified in D. melanogaster and has a pathogenic effect (Min and Benzer, 1997), and wMelPop-CLA is a strain of $w$ MelPop adapted for Ae. aegypti (McMeniman et al., 2008). Inaugural experiments in D. melanogaster determined that 
Wolbachia infection increases host resistance to the Drosophila $\mathrm{C}$ virus, Nora virus, Flock House virus, and WNV (Teixeira et al., 2008; Glaser and Meola, 2010). Subsequently, others determined that the same effect occurs in mosquitoes: The presence of Wolbachia ( $w \mathrm{Mel}$ and wMelPop-CLA strains) in Ae. aegypti mosquitoes is correlated with a reduction in DENV titer (Walker et al., 2011) and WNV titer (Hussain et al., 2013). One study determined that the amount of secreted WNV decreases significantly in Aedes cells that are also infected with Wolbachia, indicating restriction of the virus. Furthermore, it determined that the Wolbachia strain $w$ MelPop, but not $w \mathrm{Mel}$, has an inhibitory effect on WNV infection in vivo (Hussain et al., 2013). Taken together, the strain of Wolbachia is important for inhibition of WNV in Aedes mosquitoes.

Perhaps of greater biological importance for WNV is the effect of Wolbachia on Culex mosquitoes. In a study using $C x$. quinquefasciatus, researchers concluded that Wolbachia increases host resistance to WNV infection (Glaser and Meola, 2010). However, this is in contrast to another study that suggests that the presence of Wolbachia (wAlbB) can increase WNV titer in Cx. tarsalis (Dodson et al., 2014). wAlbB is a strain originally isolated from Ae. albopictus (Zhou et al., 1998).

Because of the controversial results, one study specifically compared the effects of Wolbachia strain wAlbB in Ae. aegypti on DENV and WNV (Kunjin strain). The study concluded that both somatic infection and stable transinfection of Wolbachia lead to inhibition of DENV and WNV replication and transmission (Joubert and O'Neill, 2017). Some researchers even suggest that introducing Wolbachia into the wild mosquito population will reduce DENV infection in humans (Schmidt et al., 2017), and modeling predicts that WNV could be eradicated subsequent to the introduction of Wolbachia in the ecosystem (Farkas et al., 2017).

Because Wolbachia is a bacterium, it would follow that it is priming an immune response in mosquitoes. However, this does not seem to be the case during DENV infection (Rancès et al., 2012). Rainey et al. describe hypotheses for the mechanism by which Wolbachia reduces viral titer (Rainey et al., 2014). One possible mechanism of antiviral action could be competition between Wolbachia and a virus for cellular resources. This is supported by Moreira et al. (2009) which determined that Wolbachia and DENV are not found in the same cells. Another putative mechanism is modulation of the autophagy pathway. DENV utilizes the autophagy pathway for replication (Lee et al., 2008), however, Wolbachia (wAlbB) has been shown to manipulate this pathway for its own survival (Voronin et al., 2012). This mechanism may not be relevant for all flaviviruses, as WNV does not utilize autophagy for replication in mammalian cells (Vandergaast and Fredericksen, 2012). More work will need to be completed in the insect model to determine the role of autophagy in WNV pathogenesis.

\section{THE BIRD IMMUNE RESPONSE TO WNV}

Birds are an important reservoir of WNV, as the virus replicates to high titers in several bird species (Figure 1B; Komar et al.,
2003). Additionally, the migration of bird populations aids in the distribution of WNV beyond the range of mosquitoes (Reed et al., 2003; Owen et al., 2006). Similarly to human and horse immunity, birds utilize the $2^{\prime}-5^{\prime}$-oligoadenylate synthase (OAS) pathway in the immune response to WNV. Briefly, OAS proteins detect double-stranded RNA from viruses and undergo a conformational change to synthesize $2^{\prime}-5^{\prime}$-oligoadenylates. These second messengers bind inactive RNase L, which then dimerizes to become active and cleave viral RNA. The OAS response is often utilized during flavivirus and alphavirus infections, likely because these positive-sense RNA viruses develop double-stranded RNA as replication intermediates in higher concentrations, as compared to a negative-sense RNA virus (Silverman, 2007). This response pathway ultimately inhibits the virus and induces apoptosis (Castelli et al., 1998; Tag-El-Din-Hassan et al., 2012).

While antibodies are a hallmark of adaptive immunity, passive immunity is a form of rapid immune activation, similar to innate immunity. Several bird species develop neutralizing antibodies to $\mathrm{WNV}$, with long-lasting protection over multiple WNV seasons, including the house sparrow (Passer domesticus) (Nemeth et al., 2009) and raptor species (Nemeth et al., 2008). Importantly, young chicks can receive maternally-inherited passive immunity for rapid protection from virus infection. Maternally-inherited antibodies to WNV have been measured in flamingo chicks (Phoenicopterus chilensis and Phoenicopterus ruber ruber) (Baitchman et al., 2007), Eastern screech owls (Megascops asio) (Hahn et al., 2006), and rock pigeons (Columba livia; Gibbs et al., 2005), indicating that this is an effective strategy for protecting chicks.

Additionally, there is some cross-protection in birds to multiple flavivirus types. House finches that are first challenged with St. Louis encephalitis virus (SLEV) first and then WNV have an antibody response to WNV. Interestingly, finches first challenged with WNV and then SLEV have an elevation in WNV antibody titers, but no increase in SLEV antibody titers during the second infection (Fang and Reisen, 2006). This information could be useful in vaccine design to protect birds against flavivirus infection. Perhaps antibodies to WNV could confer resistance to multiple flaviviruses, theorizing a universal flavivirus vaccine. Some researchers did vaccinate birds with the goal of saving rare species. One study used a DNA vaccine to protect captive California condors (Gymnogyps californianus) during the initial spread of WNV in the U.S. The study determined that the vaccine is safe for California condors, stimulates protective antibodies, and protects against naturally circulating WNV (Chang et al., 2007).

\section{THE HORSE IMMUNE RESPONSE TO WNV}

Horses are also susceptible to WNV infection (Figure 1F), and since its entry to the U.S. in 1999 , WNV has caused 27,726 confirmed equine cases (data through 2016; USDA APHIS, 2017). In a WNV outbreak in 2002, a survey determined that $22 \%$ of infected horses died from infection (Schuler et al., 2004). Like humans, horses have a robust immune 
response to $\mathrm{WNV}$ that utilizes both the innate and adaptive responses.

In the early immune response, horses utilize an interferonmediated (IFN) response. In one study that used WNV (Kunjin subtype) authors found increased levels of type I and type II interferon in blood leukocytes, lymph nodes, and spleen. They also noted increases in IFN- $\alpha$, CXCL10, TLR3, ISG15, and IRF7 in the brain, but no neuroinvasion of the virus (BielefeldtOhmann et al., 2017). In a project that investigated global gene expression of the central nervous system (CNS) of horses by sequencing the transcriptome of the brain and spinal cord, researchers identified gene ontology groups utilized in the WNV immune response. These include IL-15, IL-22, MAPK, and JAK/STAT signaling, as well as apoptosis pathways and B cell and $\mathrm{T}$ cell receptor expression (Bourgeois et al., 2011). These pathways also exist in humans, indicating similarities between the human and horse immune responses to WNV.

Horses also have an OAS1 response to WNV that is inducible by interferon, and variation in the horse $O A S 1$ gene has been associated with changes in WNV susceptibility (Rios et al., 2007, 2010). Furthermore, like birds, horses also mount an immune response to WNV using antibodies (Bielefeldt-Ohmann et al., 2017). Pony foals have been shown to receive maternallyinherited antibodies as a means of passive immunity (Wilkins et al., 2006). This strategy utilizes antibodies to rapidly activate the immune response to protect foals from infection.

\section{THE HUMAN IMMUNE RESPONSE TO WNV}

Because of the negative impact of WNV on the human population throughout the U.S., many researchers have characterized the human immune response to $\mathrm{WNV}$, reviewed by Suthar et al. (2013). Briefly, the viral RNA sensors RIG-I and MDA5 detect WNV intracellularly, activating the adaptor protein MAVS, leading to IRF-3 activation for interferon induction and downstream induction of interferon-stimulated genes (ISGs) (Fredericksen et al., 2004, 2008; Fredericksen and Gale, 2006). The cytokines IFN- $\alpha$ and IFN- $\beta$ are important for controlling WNV tropism by inducing an antiviral state (Samuel and Diamond, 2005). Priming an IFN response with the unrelated virus Invertebrate Iridescent virus 6 actually reduces WNV (Kunjin strain) titer in vitro (Ahlers et al., 2016). The downstream ISGs include the IFIT (interferon-induced protein with tetratricopeptide repeats) genes and viperin, which inhibit viral infection and replication (Jiang et al., 2010; Szretter et al., 2011; Gorman et al., 2016). Notably, the nonstructural protein NS5 of WNV inhibits the interferon response by preventing the expression of IFN- $\alpha$ receptor 1 on the surface of host cells (Lubick et al., 2015). The virus can also evade host restriction by IFIT proteins via 2'-O methylation of WNV (Daffis et al., 2010; Szretter et al., 2012). This strategy of antagonizing the IFN response is common to flaviviruses. ZIKV and DENV NS5 target human STAT2 for degradation (Morrison et al., 2013; Grant et al., 2016) by different mechanisms. YFV binds to STAT2 after host cells are stimulated with IFN to prevent it from binding to promoter elements (Laurent-Rolle et al., 2014).
Apoptosis is another innate immune response in mammals that restricts WNV replication, and the mechanisms of apoptosis induction have been studied in murine models. In one, mouse embryonic fibroblasts utilize CHOP (cyclic AMP response element-binding transcription factor homologous protein) to induce apoptosis and reduce WNV titer (Medigeshi et al., 2007). However, while apoptosis can be an effective method for eliminating virus from a host, it has a damaging effect on neurons. Although caspase 3 is activated during WNV infection, possibly in an attempt at an immune response, caspase 3 knockout mice have higher survival during WNV infection and less neuronal death than their wild-type counterparts (Samuel et al., 2007). Moreover, inhibition of caspase 8 during WNV infection reduces CNS tissue injury (Clarke et al., 2014). These findings suggest that the net beneficial or detrimental outcome of apoptosis as an immune response could be dependent on the type of tissue and the specific pro-apoptotic pathway activated.

While the interferon response is critical for restricting WNV, the human immune response to WNV also utilizes the OAS and RNase L pathway (Hornung et al., 2014). Indeed, a single nucleotide polymorphism in the $O A S 1 b$ gene, namely rs34137742, that contains a $\mathrm{C}$ to $\mathrm{T}$ substitution in the second intron of the gene, is a risk factor for human West Nile encephalitis and paralysis from WNV infection (Bigham et al., 2011). OAS1 has been demonstrated to undergo positive selection in Old World primates (Fish and Boissinot, 2016), indicating a historic interaction between flaviviruses like WNV and host immunity (Daugherty and Malik, 2012). This pathway is conserved in birds and horses, as discussed in earlier sections.

Passive immunity is also useful for rapid host protection to WNV. B cell and antibody-deficient ( $\mu \mathrm{MT})$ mice and B cell activating factor receptor (BAFFR)-deficient mice are susceptible to infection, but, if treated with immune sera from a wildtype mouse with antibodies to WNV, can be protected from infection (Diamond et al., 2003; Giordano et al., 2017). Strikingly, the BAFFR-deficient mice can develop sustained protective immunity after treatment with immune sera (Giordano et al., 2017). Together, this indicates that passive immunity could be utilized as a therapeutic option for human infection to induce a robust immune response. To the best of our knowledge, no studies have determined if antibodies to WNV are maternallyinherited in humans.

In summary, the animal hosts of WNV have both shared and divergent immune response pathways (Table 1). While mammals do possess an RNAi pathway like insects, the IFN immune response takes precedence as the primary innate immune response (Benitez et al., 2015). Both insects and mammals utilize apoptosis as a rapid response to virus infection. Birds, horses, and humans all utilize an OAS response and passive immunity, which are both activated rapidly during infection and are effective at restricting $\mathrm{WNV}$.

\section{THE FUTURE OF WNV RESEARCH}

Presently, no approved vaccine or therapeutic exists for human use to prevent or treat WNV infection. There are, however, 
TABLE 1 | Summary of the host responses of the animal hosts of West Nile virus.

\begin{tabular}{lllll}
\hline & Mosquito & Bird & Horse & Human \\
\hline RNAi response & Yes & Unknown & Unknown & Not utilized \\
Interferon-mediated & Possibly, using & Unknown & Yes & Yes \\
response & Vago & & & \\
Apoptosis & Yes & Unknown & Yes & Yes \\
OAS response & Absent & Yes & Yes & Yes \\
Passive immunity & Absent & Yes & Yes & Yes
\end{tabular}

Various classes of conserved host responses are noted if they are utilized in the response to WNV (yes), present in the host, but not utilized in the response to WNV (not utilized), or not present/undiscovered in the host (absent).

four approved horse vaccines in use in the U.S., which have greatly aided in the reduction of equine cases. Veterinary options include two inactivated whole virus vaccines, a non-replicating live recombinant canary pox vector vaccine, and an inactivated flavivirus chimera vaccine (Ishikawa et al., 2014; Balasuriya et al., 2015). A number of human vaccines have been proposed, with some in clinical trials.

One promising vaccine is ChimeriVax-WN02, which is a live, attenuated vaccine created by inserting the genes for the premembrane (prM) and envelope (E) proteins from WNV into the yellow fever 17D clone (Arroyo et al., 2004). The vaccine completed a successful phase I clinical trial and two phase II clinical trials (Monath et al., 2006; Biedenbender et al., 2011; Dayan et al., 2012). Another chimeric vaccine that passed a phase I trial, rWN/DEN4 $\Delta 30$, also utilizes prM and E from WNV but uses the live attenuated vaccine candidate rDEN4 $\Delta 30$ as a vector (Durbin et al., 2013). Another strategy utilizes a DNA vaccine with the prM and E proteins of WNV, either with the CMV promoter (Martin et al., 2007) or a modified CMV promoter (CMV/R) (Ledgerwood et al., 2011). Both

\section{REFERENCES}

Ahlers, L. R. H., Bastos, R. G., Hiroyasu, A., and Goodman, A. G. (2016). Invertebrate iridescent virus 6, a DNA virus, stimulates a mammalian innate immune response through RIG-I-like receptors. PLoS ONE 11:e0166088. doi: 10.1371/journal.pone.0166088

Andersen, L. K., and Davis, M. D. (2017). Climate change and the epidemiology of selected tick-borne and mosquito-borne diseases: update from the international society of dermatology climate change task force. Int. J. Dermatol. 56, 252-259. doi: 10.1111/ijd. 13438

Arroyo, J., Miller, C., Catalan, J., Myers, G. A., Ratterree, M. S., Trent, D. W., et al. (2004). ChimeriVax-west nile virus live-attenuated vaccine: preclinical evaluation of safety, immunogenicity, and efficacy. J. Virol. 78, 12497-12507. doi: 10.1128/JVI.78.22.12497-12507.2004

Baitchman, E. J., Tlusty, M. F., and Murphy, H. W. (2007). Passive transfer of maternal antibodies to west nile virus in flamingo chicks (Phoenicopterus Chilensis and Phoenicopterus ruber ruber). J. Zoo Wildl. Med. 38, 337-340. doi: 10.1638/1042-7260(2007)038[0337:PTOMAT]2.0.CO;2

Balasuriya, U., Johnson, A., Lunn, D. P., Morgan, K., Pusterla, N., Timoney, P., et al. (2015). AAEP Vaccination Guidelines. Available online at: https://aaep. org/guidelines/vaccination-guidelines/core-vaccination-guidelines/west-nilevirus (Accessed January 5, 2018). versions of this vaccine completed successful phase I clinical trials.

Despite these successful early clinical trials, no WNV vaccine has moved into phase III trials. Some challenges for a phase III trial for a WNV vaccine are discussed in Ishikawa et al. (2014). One notable impediment is the low and sporadic incidence of WNV activity, which would make it difficult to establish vaccine efficacy. Because of the logistical challenges of developing and licensing a vaccine for WNV, perhaps a more feasible avenue for prevention is the introduction of Wolbachia into the mosquito population. As discussed in an earlier section, Wolbachia reduces flavivirus titer in mosquitoes, and models predict that WNV eradication is possible with the introduction of Wolbachia (Farkas et al., 2017). Certainly, great caution should be taken to determine if the introduction of Wolbachia into the Culex population would have any detrimental effects on the greater ecosystem.

\section{AUTHOR CONTRIBUTIONS}

LA wrote the manuscript in consultation with AG.

\section{FUNDING}

Research in the Goodman lab is supported by NIH Grant R21 AI128103 to AG, NIH/NIGMS funded pre-doctoral fellowship T32 GM008336 and a Poncin Fellowship to LA, the Stanley L. Adler Research Fund, and the Mary V. Schindler Equine Research Endowment.

\section{ACKNOWLEDGMENTS}

We thank A.C. Carver for providing editorial comments for our manuscript.

Barr, A. R. (1957). The distribution of Culex p. pipiens and C. p. quinquefasciatus in North America. Am. J. Trop. Med. Hyg. 6, 153-165. doi: 10.4269/ajtmh.1957.6.153

Benitez, A. A., Spanko, L. A., Bouhaddou, M., Sachs, D., and tenOever, B. R. (2015). Engineered mammalian RNAi can elicit antiviral protection that negates the requirement for the interferon response. Cell Rep. 13, 1456-1466. doi: 10.1016/j.celrep.2015.10.020

Biedenbender, R., Bevilacqua, J., Gregg, A. M., Watson, M., and Dayan, G. (2011). Phase II, randomized, double-blind, placebo-controlled, multicenter study to investigate the immunogenicity and safety of a west nile virus vaccine in healthy adults. J. Infect. Dis. 203, 75-84. doi: 10.1093/infdis/jiq003

Bielefeldt-Ohmann, H., Bosco-Lauth, A., Hartwig, A. E., Uddin, M. J., Barcelon, J., Suen, W. W., et al. (2017). Characterization of non-lethal West Nile Virus (WNV) infection in horses: subclinical pathology and innate immune response. Microb. Pathog. 103, 71-79. doi: 10.1016/j.micpath.2016.12.018

Bigham, A. W., Buckingham, K. J., Husain, S., Emond, M. J., Bofferding, K. M., Gildersleeve, H., et al. (2011). Host genetic risk factors for West Nile Virus infection and disease progression. PLOS ONE 6:e24745. doi: 10.1371/journal.pone.0024745

Bourgeois, M. A., Denslow, N. D., Seino, K. S., Barber, D. S., and Long, M. T. (2011). Gene expression analysis in the thalamus and cerebrum of horses experimentally infected with West Nile Virus. PLoS ONE 6:e24371. doi: 10.1371/journal.pone.0024371 
Brackney, D. E., Beane, J. E., and Ebel, G. D. (2009). RNAi targeting of west nile virus in mosquito midguts promotes virus diversification. PLoS Pathog. 5:e1000502. doi: 10.1371/journal.ppat.1000502

Brackney, D. E., Schirtzinger, E. E., Harrison, T. D., Ebel, G. D., and Hanley, K. A. (2015). Modulation of flavivirus population diversity by RNA interference. J. Virol. 89, 4035-4039. doi: 10.1128/JVI.02612-14

Brinton, M. A. (2013). Replication cycle and molecular biology of the West Nile Virus. Viruses 6, 13-53. doi: 10.3390/v6010013

Castelli, J. C., Hassel, B. A., Maran, A., Paranjape, J., Hewitt, J. A., Li, X., et al. (1998). The role of $2^{\prime}-5^{\prime}$ oligoadenylate-activated ribonuclease $\mathrm{L}$ in apoptosis. Cell Death Differ. 5, 313-320. doi: 10.1038/sj.cdd.4400352

Chang, G. J., Davis, B. S., Stringfield, C., and Lutz, C. (2007). Prospective immunization of the endangered California condors (Gymnogyps californianus) protects this species from lethal West Nile Virus infection. Vaccine 25, 2325-2330. doi: 10.1016/j.vaccine.2006.11.056

Chapman, E. G., Costantino, D. A., Rabe, J. L., Moon, S. L., Wilusz, J., Nix, J. C., et al. (2014). The structural basis of pathogenic subgenomic flavivirus RNA (sfRNA) production. Science 344, 307-310. doi: 10.1126/science.1250897

Chen, C. C., Jenkins, E., Epp, T., Waldner, C., Curry, P. S., and Soos, C. (2013). Climate change and West Nile Virus in a highly endemic region of north america. Int. J. Environ. Res. Public Health 10, 3052-3071. doi: $10.3390 /$ ijerph 10073052

Chotkowski, H. L., Ciota, A. T., Jia, Y., Puig-Basagoiti, F., Kramer, L. D., Shi, P. Y., et al. (2008). West Nile Virus infection of Drosophila melanogaster induces a protective RNAi response. Virology 377, 197-206. doi: $10.1016 /$ j.virol.2008.04.021

Ciota, A. T., Styer, L. M., Meola, M. A., and Kramer, L. D. (2011). The costs of infection and resistance as determinants of West Nile virus susceptibility in Culex mosquitoes. BMC Ecol. 11:23. doi: 10.1186/1472-6785-11-23

Clarke, P., Leser, J. S., Quick, E. D., Dionne, K. R., Beckham, J. D., and Tyler, K. L. (2014). Death receptor-mediated apoptotic signaling is activated in the brain following infection with West Nile Virus in the absence of a peripheral immune response. J. Virol. 88, 1080-1089. doi: 10.1128/JVI.02944-13

Colpitts, T. M., Cox, J., Vanlandingham, D. L., Feitosa, F. M., Cheng, G., Kurscheid, S., et al. (2011). Alterations in the aedes aegypti transcriptome during infection with west nile, dengue and yellow fever viruses. PLoS Pathog. 7:e1002189. doi: 10.1371/journal.ppat.1002189

Daffis, S., Szretter, K. J., Schriewer, J., Li, J., Youn, S., Errett, J., et al. (2010). 2' O methylation of the viral mRNA cap evades host restriction by IFIT family members. Nature 468, 452-456. doi: 10.1038/nature09489

Darsie, R. F., and Ward, R. A. (2005). Identification and Geographical Distribution of the Mosquitos of North America. North of Mexico, University Press of Florida.

Daugherty, M. D., and Malik, H. S. (2012). Rules of engagement: molecular insights from host-virus arms races. Annu. Rev. Genet. 46, 677-700. doi: 10.1146/annurev-genet-110711-155522

Dayan, G. H., Bevilacqua, J., Coleman, D., Buldo, A., and Risi, G. (2012). Phase II, dose ranging study of the safety and immunogenicity of single dose West Nile vaccine in healthy adults $\geq 50$ years of age. Vaccine 30, 6656-6664. doi: 10.1016/j.vaccine.2012.08.063

Diamond, M. S., Shrestha, B., Marri, A., Mahan, D., and Engle, M. (2003). $B$ cells and antibody play critical roles in the immediate defense of disseminated infection by West Nile Encephalitis Virus. J. Virol. 77, 2578-2586. doi: 10.1128/JVI.77.4.2578-2586.2003

Dodson, B. L., Hughes, G. L., Paul, O., Matacchiero, A. C., Kramer, L. D., and Rasgon, J. L. (2014). Wolbachia enhances West Nile Virus (WNV) infection in the Mosquito Culex tarsalis. PLoS Negl. Trop. Dis. 8:e2965. doi: 10.1371/journal.pntd.0002965

Dohm, D. J., Sardelis, M. R., and Turell, M. J. (2002). Experimental vertical transmission of West Nile Virus by Culex pipiens (Diptera: Culicidae). J. Med. Entomol. 39, 640-644. doi: 10.1603/0022-2585-39.4.640

Durbin, A. P., Wright, P. F., Cox, A., Kagucia, W., Elwood, D., Henderson, S., et al. (2013). The live attenuated chimeric vaccine $\mathrm{rWN} / \mathrm{DEN} 4 \Delta 30$ is well-tolerated and immunogenic in healthy flavivirus-naïve adult volunteers. Vaccine 31, 5772-5777. doi: 10.1016/j.vaccine.2013.07.064

Fang, Y., and Reisen, W. K. (2006). Previous infection with West Nile or St. Louis encephalitis viruses provides cross protection during reinfection in house finches. Am. J. Trop. Med. Hyg. 75, 480-485. doi: 10.4269/ajtmh.2006.75.480
Farkas, J. Z., Gourley, S. A., Liu, R., and Yakubu, A. A. (2017). Modelling Wolbachia infection in a sex-structured mosquito population carrying West Nile virus. J. Math. Biol. 75, 621-647. doi: 10.1007/s00285-017-1096-7

Fish, I., and Boissinot, S. (2016). Functional evolution of the OAS1 viral sensor: insights from old world primates. Infect. Genet. Evol. 44, 341-350. doi: 10.1016/j.meegid.2016.07.005

Fredericksen, B. L., and Gale, M. (2006). West Nile Virus evades activation of interferon regulatory factor 3 through RIG-I-dependent and -independent pathways without antagonizing host defense signaling. J. Virol. 80, 2913-2923. doi: 10.1128/JVI.80.6.2913-2923.2006

Fredericksen, B. L., Keller, B. C., Fornek, J., Katze, M. G., and Gale, M. (2008). Establishment and maintenance of the innate antiviral response to West Nile Virus involves both RIG-I and MDA5 signaling through IPS-1. J. Virol. 82, 609-616. doi: 10.1128/JVI.01305-07

Fredericksen, B. L., Smith, M., Katze, M. G., Shi, P. Y., and Gale, M. (2004). The host response to West Nile Virus infection limits viral spread through the activation of the interferon regulatory factor 3 pathway. J. Virol. 78, 7737-7747. doi: 10.1128/JVI.78.14.7737-7747.2004

Gibbs, S. E., Hoffman, D. M., Stark, L. M., Marlenee, N. L., Blitvich, B. J., Beaty, B. J., et al. (2005). Persistence of antibodies to West Nile Virus in naturally infected rock pigeons (Columba livia). Clin. Diagn. Lab. Immunol. 12, 665-667. doi: 10.1128/CDLI.12.5.665-667.2005

Giordano, D., Draves, K. E., Young, L. B., Roe, K., Bryan, M. A., Dresch, C., et al. (2017). Protection of mice deficient in mature B cells from West Nile virus infection by passive and active immunization. PLoS Pathog. 13:e1006743. doi: 10.1371/journal.ppat.1006743

Girard, Y. A., Schneider, B. S., McGee, C. E., Wen, J., Han, V. C., Popov, V., et al. (2007). Salivary gland morphology and virus transmission during long-term cytopathologic West Nile virus infection in Culex mosquitoes. Am. J. Trop. Med. Hyg. 76, 118-128. doi: 10.4269/ajtmh.2007.76.118

Glaser, R. L., and Meola, M. A. (2010). The native Wolbachia endosymbionts of Drosophila melanogaster and Culex quinquefasciatus increase host resistance to West Nile Virus infection. PLoS ONE 5:e11977. doi: 10.1371/journal.pone.0011977

Gorman, M. J., Poddar, S., Farzan, M., and Diamond, M. S. (2016). The interferonstimulated gene Ifitm3 restricts West Nile Virus infection and pathogenesis. J. Virol. 90, 8212-8225. doi: 10.1128/JVI.00581-16

Grant, A., Ponia, S. S., Tripathi, S., Balasubramaniam, V., Miorin, L., Sourisseau, M., et al. (2016). Zika virus targets human STAT2 to inhibit type I interferon signaling. Cell Host Microbe 19, 882-890. doi: 10.1016/j.chom.2016.05.009

Hahn, D. C., Nemeth, N. M., Edwards, E., Bright, P. R., and Komar, N. (2006). Passive West Nile Virus antibody transfer from maternal eastern screech-Owls (Megascops asio) to progeny. Avian Dis. 50, 454-455. doi: 10.1637/7509-012606R1.1

Hertig, M., and Wolbach, S. B. (1924). Studies on rickettsia-like micro-organisms in insects. J. Med. Res. 44, 329-374.7.

Hongoh, V., Berrang-Ford, L., Scott, M. E., and Lindsay, L. R. (2012). Expanding geographical distribution of the mosquito, Culex pipiens, in Canada under climate change. Appl. Geogr. 33, 53-62. doi: 10.1016/j.apgeog.2011.05.015

Hornung, V., Hartmann, R., Ablasser, A., and Hopfner, K. P. (2014). OAS proteins and cGAS: unifying concepts in sensing and responding to cytosolic nucleic acids. Nat. Rev. Immunol. 14, 521-528. doi: 10.1038/nri3719

Hussain, M., Lu, G., Torres, S., Edmonds, J. H., Kay, B. H., Khromykh, A. A., et al. (2013). Effect of Wolbachia on replication of West Nile Virus in a mosquito cell line and adult mosquitoes. J. Virol. 87, 851-858. doi: 10.1128/JVI.018 37-12

Ishikawa, T., Yamanaka, A., and Konishi, E. (2014). A review of successful flavivirus vaccines and the problems with those flaviviruses for which vaccines are not yet available. Vaccine 32, 1326-1337. doi: 10.1016/j.vaccine.2014.01.040

Janssen, N., Fernandez-Salas, I., Díaz González, E. E., Gaytan-Burns, A., Medinade la Garza, C. E., Sanchez-Casas, R. M., et al. (2015). Mammalophilic feeding behaviour of Culex quinquefasciatus mosquitoes collected in the cities of Chetumal and Cancun, Yucatán Peninsula, Mexico. Trop. Med. Int. Health 20, 1488-1491. doi: 10.1111/tmi.12587

Jiang, D., Weidner, J. M., Qing, M., Pan, X. B., Guo, H., Xu, C., et al. (2010). Identification of five interferon-induced cellular proteins that inhibit West Nile Virus and dengue virus infections. J. Virol. 84, 8332-8341. doi: 10.1128/JVI.02199-09 
Johnson, B. J., Robson, M. G., and Fonseca, D. M. (2015). Unexpected spatiotemporal abundance of infected Culex restuans suggest a greater role as a West Nile virus vector for this native species. Infect. Genet. Evol. 31, 40-47. doi: 10.1016/j.meegid.2015.01.007

Johnson, K. N. (2015). The impact of Wolbachia on virus infection in mosquitoes. Viruses 7, 5705-5717. doi: 10.3390/v7112903

Jones, C. I., Zabolotskaya, M. V., and Newbury, S. F. (2012). The $5^{\prime} \rightarrow 3^{\prime}$ exoribonuclease XRN1/Pacman and its functions in cellular processes and development. Wiley Interdiscip. Rev. RNA 3, 455-468. doi: 10.1002/wrna.1109

Joubert, D. A., and O'Neill, S. L. (2017). Comparison of stable and transient Wolbachia infection models in aedes aegypti to block dengue and West Nile Viruses. PLoS Negl. Trop. Dis. 11:e0005275. doi: 10.1371/journal.pntd.0005275

Kilpatrick, A. M., Fonseca, D. M., Ebel, G. D., Reddy, M. R., and Kramer, L. D. (2010). Spatial and temporal variation in vector competence of Culex pipiens and Cx. restuans mosquitoes for West Nile virus. Am. J. Trop. Med. Hyg. 83, 607-613. doi: 10.4269/ajtmh.2010.10-0005

Komar, N., Langevin, S., Hinten, S., Nemeth, N., Edwards, E., Hettler, D., et al. (2003). Experimental infection of North American birds with the New York 1999 strain of West Nile Virus. Emerg. Infect. Dis. 9, 311-322. doi: 10.3201/eid0903.020628

Laurent-Rolle, M., Morrison, J., Rajsbaum, R., Macleod, J. M. L., Pisanelli, G., Pham, A., et al. (2014). The interferon signaling antagonist function of yellow fever virus NS5 protein is activated by type I interferon. Cell Host Microbe 16, 314-327. doi: 10.1016/j.chom.2014.07.015

Ledgerwood, J. E., Pierson, T. C., Hubka, S. A., Desai, N., Rucker, S., Gordon, I. J., et al. (2011). A West Nile Virus DNA vaccine utilizing a modified promoter induces neutralizing antibody in younger and older healthy adults in a phase I clinical trial. J. Infect. Dis. 203, 1396-1404. doi: 10.1093/infdis/ jir054

Lee, Y. R., Lei, H. Y., Liu, M. T., Wang, J. R., Chen, S. H., Jiang-Shieh, Y. F., et al. (2008). Autophagic machinery activated by dengue virus enhances virus replication. Virology 374, 240-248. doi: 10.1016/j.virol.2008.02.016

Lubick, K. J., Robertson, S. J., McNally, K. L., Freedman, B. A., Rasmussen, A. L., Taylor, R. T., et al. (2015). Flavivirus antagonism of type I interferon signaling reveals prolidase as a regulator of IFNAR1 surface expression. Cell Host Microbe 18, 61-74. doi: 10.1016/j.chom.2015.06.007

Lujan, D. A., Greenberg, J. A., Hung, A. S., Dimenna, M. A., and Hofkin, B. V. (2014). Evaluation of seasonal feeding patterns of West Nile Virus vectors in Bernalillo County, New Mexico, United States: implications for disease transmission. J. Med. Entomol. 51, 264-268. doi: 10.1603/ME13163

Mackay, A. J., Kramer, W. L., Meece, J. K., Brumfield, R. T., and Foil, L. D. (2010). Host feeding patterns of Culex Mosquitoes (Diptera: Culicidae) in east baton rouge Parish, Louisiana. J. Med. Entomol. 47, 238-248. doi: 10.1093/jmedent/47.2.238

Martin, J. E., Pierson, T. C., Hubka, S., Rucker, S., Gordon, I. J., Enama, M. E., et al. (2007). A West Nile Virus DNA vaccine induces neutralizing antibody in healthy adults during a phase 1 clinical trial. J. Infect. Dis. 196, 1732-1740. doi: $10.1086 / 523650$

McMeniman, C. J., Lane, A. M., Fong, A. W. C., Voronin, D. A., Iturbe-Ormaetxe, I., Yamada, R., et al. (2008). Host adaptation of a Wolbachia strain after long-term serial passage in mosquito cell lines. Appl. Environ. Microbiol. 74, 6963-6969. doi: 10.1128/AEM.01038-08

Medigeshi, G. R., Lancaster, A. M., Hirsch, A. J., Briese, T., Lipkin, W. I., DeFilippis, V., et al. (2007). West Nile Virus infection activates the unfolded protein response, leading to CHOP induction and apoptosis. J. Virol. 81, 10849-10860. doi: 10.1128/JVI.01151-07

Min, K. T., and Benzer, S. (1997). Wolbachia, normally a symbiont of Drosophila, can be virulent, causing degeneration and early death. Proc. Natl. Acad. Sci. U.S.A. 94, 10792-10796. doi: 10.1073/pnas.94.20.10792

Molaei, G., Andreadis, T. G., Armstrong, P. M., Anderson, J. F., and Vossbrinck, C. R. (2006). Host feeding patterns of Culex mosquitoes and West Nile Virus transmission, Northeastern United States. Emerg. Infect. Dis. 12, 468-474. doi: 10.3201/eid1203.051004

Monath, T. P., Liu, J., Kanesa-Thasan, N., Myers, G. A., Nichols, R., Deary, A., et al. (2006). A live, attenuated recombinant West Nile virus vaccine. Proc. Natl. Acad. Sci. U.S.A. 103, 6694-6699. doi: 10.1073/pnas.0601932103

Moon, S. L., Dodd, B. J. T., Brackney, D. E., Wilusz, C. J., Ebel, G. D., and Wilusz, J. (2015). Flavivirus sfRNA suppresses antiviral RNA interference in cultured cells and mosquitoes and directly interacts with the RNAi machinery. Virology 485, 322-329. doi: 10.1016/j.virol.2015.08.009

Moreira, L. A., Iturbe-Ormaetxe, I., Jeffery, J. A., Lu, G., Pyke, A. T., Hedges, L. M., et al. (2009). A Wolbachia symbiont in Aedes aegypti limits infection with dengue, chikungunya, and plasmodium. Cell 139, 1268-1278. doi: 10.1016/j.cell.2009.11.042

Morin, C. W., and Comrie, A. C. (2013). Regional and seasonal response of a West Nile Virus vector to climate change. Proc. Natl. Acad. Sci. U.S.A. 110, 15620-15625. doi: 10.1073/pnas.1307135110

Morrison, J., Laurent-Rolle, M., Maestre, A. M., Rajsbaum, R., Pisanelli, G., Simon, V., et al. (2013). Dengue virus Co-opts UBR4 to degrade STAT2 and antagonize type I interferon signaling. PLoS Pathog. 9:e1003265. doi: 10.1371/journal.ppat.1003265

Nemeth, N. M., Kratz, G. E., Bates, R., Scherpelz, J. A., Bowen, R. A., and Komar, N. (2008). Naturally induced humoral immunity to West Nile Virus infection in raptors. Ecohealth 5, 298-304. doi: 10.1007/s10393-008-0183-z

Nemeth, N. M., Oesterle, P. T., and Bowen, R. A. (2009). Humoral immunity to West Nile Virus is long-lasting and protective in the house sparrow (Passer domesticus). Am. J. Trop. Med. Hyg. 80, 864-869. doi: 10.4269/ajtmh.2009.80.864

Olson, K. E., and Blair, C. D. (2015). Arbovirus-mosquito interactions: RNAi pathway. Curr. Opin. Virol. 15, 119-126. doi: 10.1016/j.coviro.2015.10.001

Owen, J., Moore, F., Panella, N., Edwards, E., Bru, R., Hughes, M., et al. (2006). Migrating birds as dispersal vehicles for West Nile Virus. Ecohealth 3:79. doi: 10.1007/s10393-006-0025-9

Paradkar, P. N., Duchemin, J. B., Voysey, R., and Walker, P. J. (2014). Dicer-2-dependent activation of Culex vago occurs via the TRAF-Rel2 signaling pathway. PLoS Negl. Trop. Dis. 8:e2823. doi: 10.1371/journal.pntd. 0002823

Paradkar, P. N., Trinidad, L., Voysey, R., Duchemin, J. B., and Walker, P. J. (2012). Secreted Vago restricts West Nile virus infection in Culex mosquito cells by activating the Jak-STAT pathway. Proc. Natl. Acad. Sci. U.S.A. 109, 18915-18920. doi: 10.1073/pnas.1205231109

Petersen, L. R., Brault, A. C., and Nasci, R. S. (2013). West Nile Virus: review of the literature. JAMA 310, 308-315. doi: 10.1001/jama.2013.8042

Rainey, S. M., Shah, P., Kohl, A., and Dietrich, I. (2014). Understanding the Wolbachia-mediated inhibition of arboviruses in mosquitoes: progress and challenges. J. Gen. Virol. 95, 517-530. doi: 10.1099/vir.0.057422-0

Rancès, E., Ye, Y. H., Woolfit, M., McGraw, E. A., and O’Neill, S. L. (2012). The Relative importance of innate immune priming in Wolbachia-mediated dengue interference. PLoS Pathog. 8:e1002548. doi: 10.1371/journal.ppat.1002548

Rasgon, J. L., and Scott, T. W. (2004). An initial survey for Wolbachia (Rickettsiales: Rickettsiaceae) infections in selected California mosquitoes (Diptera: Culicidae). J. Med. Entomol. 41, 255-257. doi: 10.1603/0022-2585-41.2.255

Reed, K. D., Meece, J. K., Henkel, J. S., and Shukla, S. K. (2003). Birds, migration and emerging zoonoses: West Nile Virus, Lyme Disease, influenza a and enteropathogens. Clin. Med. Res. 1, 5-12. doi: 10.3121/cmr.1.1.5

Reisen, W. K. (2012). The contrasting bionomics of Culex mosquitoes in western North America. J. Am. Mosq. Control Assoc. 28, 82-91. doi: 10.2987/8756-971X-28.4.82

Rios, J. J., Fleming, J. G. W., Bryant, U. K., Carter, C. N., Huber, J. C. Jr., Long, M. T., et al. (2010). OAS1 polymorphisms are associated with susceptibility to West Nile encephalitis in horses. PLoS ONE 5:e10537. doi: 10.1371/journal.pone.0010537

Rios, J. J., Perelygin, A. A., Long, M. T., Lear, T. L., Zharkikh, A. A., Brinton, M. A., et al. (2007). Characterization of the equine 2'-5' oligoadenylate synthetase 1 (OAS1) and ribonuclease L (RNASEL) innate immunity genes. BMC Genomics 8:313. doi: 10.1186/1471-2164-8-313

Samuel, M. A., and Diamond, M. S. (2005). Alpha/Beta interferon protects against lethal West Nile Virus infection by restricting cellular tropism and enhancing neuronal survival. J. Virol. 79, 13350-13361. doi: 10.1128/JVI.79.21.13350-13361.2005

Samuel, M. A., Morrey, J. D., and Diamond, M. S. (2007). Caspase 3-dependent cell death of neurons contributes to the pathogenesis of West Nile Virus encephalitis. J. Virol. 81, 2614-2623. doi: 10.1128/JVI.02311-06

Sardelis, M. R., Turell, M. J., Dohm, D. J., and O'Guinn, M. L. (2001). Vector competence of selected North American Culex and Coquillettidia 
mosquitoes for West Nile virus. Emerg. Infect. Dis. 7, 1018-1022. doi: 10.3201/eid0706.010617

Schmidt, T. L., Barton, N. H., Rašić, G., Turley, A. P., Montgomery, B. L., IturbeOrmaetxe, I., et al. (2017). Local introduction and heterogeneous spatial spread of dengue-suppressing Wolbachia through an urban population of Aedes aegypti. PLoS Biol. 15:e2001894. doi: 10.1371/journal.pbio.2001894

Schuler, L. A., Khaitsa, M. L., Dyer, N. W., and Stoltenow, C. L. (2004). Evaluation of an outbreak of West Nile virus infection in horses: 569 cases (2002). J. Am. Vet. Med. Assoc. 225, 1084-1089. doi: 10.2460/javma.2004.225.1084

Silverman, R. H. (2007). Viral Encounters with 2',5'-Oligoadenylate synthetase and RNase L during the interferon antiviral response. J. Virol. 81, 12720-12729. doi: 10.1128/JVI.01471-07

Styer, L. M., Meola, M. A., and Kramer, L. D. (2007). West Nile virus infection decreases fecundity of Culex tarsalis females. J. Med. Entomol. 44, 1074-1085. doi: 10.1093/jmedent/44.6.1074

Suthar, M. S., Diamond, M. S., and Gale, M. Jr. (2013). West Nile virus infection and immunity. Nat. Rev. Microbiol. 11, 115-128. doi: 10.1038/nrmicro2950

Szretter, K. J., Brien, J. D., Thackray, L. B., Virgin, H. W., Cresswell, P., and Diamond, M. S. (2011). The interferon-inducible gene viperin restricts West Nile Virus pathogenesis. J. Virol. 85, 11557-11566. doi: 10.1128/JVI.05519-11

Szretter, K. J., Daniels, B. P., Cho, H., Gainey, M. D., Yokoyama, W. M. Jr., Gale, M., et al. (2012). 2'-O Methylation of the viral mRNA cap by West Nile Virus evades Ifit1-dependent and -independent mechanisms of host restriction in vivo. PLoS Pathog. 8:e1002698. doi: 10.1371/journal.ppat.1002698

Tag-El-Din-Hassan, H. T., Sasaki, N., Moritoh, K., Torigoe, D., Maeda, A., and Agui, T. (2012). The chicken 2'-5' oligoadenylate synthetase a inhibits the replication of West Nile virus. Jpn. J. Vet. Res. 60, 95-103. doi: 10.13140/2.1.4193.5681

Teixeira, L., Ferreira, Á., and Ashburner, M. (2008). The bacterial symbiont Wolbachia induces resistance to RNA viral infections in Drosophila melanogaster. PLoS Biol. 6:e1000002. doi: 10.1371/journal.pbio.1000002

Turell, M. J., O'Guinn, M. L., Dohm, D. J., and Jones, J. W. (2001). Vector competence of North American Mosquitoes (Diptera: Culicidae) for West Nile Virus. J. Med. Entomol. 38, 130-134. doi: 10.1603/0022-2585-38.2.130

Turell, M. J., O'Guinn, M. L., Dohm, D. J., Webb, J. P., and Sardelis, M. R. (2002). Vector competence of Culex tarsalis from orange County, California, for West Nile virus. Vector Borne Zoonotic Dis. 2, 193-196. doi: $10.1089 / 15303660260613756$

USDA APHIS (2017). West Nile Virus Maps- States with Equine Cases. The Animal and Plant Health Inspection Service. Available online at: https://www.aphis. usda.gov/aphis/ourfocus/animalhealth/animal-disease-information/horsedisease-information/sa_west_nile_virus/ct_wnv_distribution_maps (Accessed January 5, 2018).
Vaidyanathan, R., and Scott, T. W. (2006). Apoptosis in mosquito midgut epithelia associated with West Nile virus infection. Apoptosis 11, 1643-1651. doi: 10.1007/s10495-006-8783-y

Vandergaast, R., and Fredericksen, B. L. (2012). West Nile Virus (WNV) replication is independent of autophagy in mammalian cells. PLOS ONE 7:e45800. doi: 10.1371/journal.pone.0045800

Voronin, D., Cook, D. A. N., Steven, A., and Taylor, M. J. (2012). Autophagy regulates Wolbachia populations across diverse symbiotic associations. Proc. Natl. Acad. Sci. U.S.A. 109, E1638-E1646. doi: 10.1073/pnas.12035 19109

Walker, T., Johnson, P. H., Moreira, L. A., Iturbe-Ormaetxe, I., Frentiu, F. D., McMeniman, C. J., et al. (2011). The wMel Wolbachia strain blocks dengue and invades caged Aedes aegypti populations. Nature 476, 450-453. doi: $10.1038 /$ nature10355

Wilkins, P. A., Glaser, A. L., and McDonnell, S. M. (2006). Passive transfer of naturally acquired specific immunity against West Nile Virus to foals in a semi-feral pony herd. J. Vet. Intern. Med. 20, 1045-1047. doi: 10.1111/j.1939-1676.2006.tb01828.x

Woolfit, M., Iturbe-Ormaetxe, I., Brownlie, J. C., Walker, T., Riegler, M., Seleznev, A., et al. (2013). Genomic evolution of the pathogenic Wolbachia strain, wMelPop. Genome Biol. Evol. 5, 2189-2204. doi: 10.1093/gbe/ evt169

WHO (2011). World Health Organization Fact Sheet on West Nile virus: No354. Available online at: http://www.who.int/mediacentre/factsheets/fs354/ en/ (Accessed January 5, 2018).

Zhou, W., Rousset, F., and O'Neil, S. (1998). Phylogeny and PCR-based classification of Wolbachia strains using wsp gene sequences. Proc. R. Soc. B Biol. Sci. 265, 509-515.

Zug, R., and Hammerstein, P. (2012). Still a host of hosts for Wolbachia: analysis of recent data suggests that $40 \%$ of terrestrial arthropod species are infected. PLoS ONE 7:e38544. doi: 10.1371/journal.pone. 0038544

Conflict of Interest Statement: The authors declare that the research was conducted in the absence of any commercial or financial relationships that could be construed as a potential conflict of interest.

Copyright () 2018 Ahlers and Goodman. This is an open-access article distributed under the terms of the Creative Commons Attribution License (CC BY). The use, distribution or reproduction in other forums is permitted, provided the original author(s) and the copyright owner are credited and that the original publication in this journal is cited, in accordance with accepted academic practice. No use, distribution or reproduction is permitted which does not comply with these terms. 